R O C ZNIKI HUMAN IS T Y C Z N E

Tom LXVIII, zeszyt 5 - 2020

ZESZYT SPECJALNY / SPECIALE UITGAVE

DOI: http://dx.doi.org/10.18290/rh20685sp-11

\title{
DE INVOEGING VAN DE GLIJKLANKEN [J] EN [W] ALS POGING TOT SPANNINGIMITATIE BIJ DE UITSPRAAK VAN DE NEDERLANDSE KLINKERS [E], [Y] EN [O] DOOR POOLSTALIGE LEERDERS
}

\begin{abstract}
A b stract. In de tekst wordt de uitspraak van de Nederlandse klinkers [e], [y] en [o] door Poolstalige leerders behandeld. Naast een simpele subsitutie van de Nederlandse gespannen klinker door een Poolse (ongespannen) klinker, kan regelmatig worden vastgesteld dat de Nederlandse klinker gerealiseerd wordt als een combinatie van de Poolse klinker en de glijklank [j] of [w]. Gedetailleerde analyse van de data toont dat de frequentie van klinker+glijklank combinaties verschillend is en dat de invoeging van de glijklank gekoppeld is aan het niveau van het Nederlands (ze begint op A2-niveau). De glijklankinvoeging kan derhalve worden gezien als een poging om de spanning van de Nederlandse klinker te imiteren (spanning is geen distinctief kenmerk in het Pools), wat van de ontwikkeling van auditieve en articulatorische vaardigheden getuigt.
\end{abstract}

Trefwoorden: fonetiek; uitspraak; Nederlands; gespannen klinker; glijklank; uitspraakdidactiekerlands.

\section{INLEIDING}

Dat het overgaan van de moedertaal naar de vreemde taal - vooral wat de uitspraak betreft - niet makkelijk is, is vanzelfsprekend. De interesse voor uitspraaktraining blijft om die reden groeien en daarom wordt er telkens aan nieuw lesmateriaal gewerkt. Toch is de communicatieve werkelijkheid veel ingewikkelder dan de oefeningen die vaak op een theoretische vergelijking van fonologische of fonetische systemen van twee talen gebaseerd zijn. Waar de talen in contact komen, ontstaat namelijk een grijze zone die vele

Dr. ZuZAnna Czerwonka-WaJda is verbonden aan de Katedra Filologii Niderlandzkiej (Vakgroep Nederlandse Filologie) van de Universiteit van Wrocław. Correspondentieadres: Katedra Filologii Niderlandzkiej, Uniwersytet Wrocławski, ul. Kuźnicza 21-22, 50-138 Wrocław, Polen; e-mail: zuzana.czerwonka@uwr.edu.pl. ORCID: https://orcid.org/0000-0003-2578-1387. 
verschillende en creatieve overgangsvormen kent. De in de titel genoemde invoeging van de glijklanken is hier een goed voorbeeld van.

Ook is het soms moeilijk uitspraakleerboeken te vinden die uitspraakproblemen in een concreet taalpaar adequaat oppakken, vooral als het aantal leerders relatief klein is. Het Nederlands is hier een goed voorbeeld van: alleen al in de laatste tien jaar zijn er in het kader van NVT enkele omvangrijke uitspraakleerboeken verschenen (o.a. Blomme et al.; Sleeuwen en Spaan; Kampen et al.; Veen et al.; Thio en Verboog; Timmermans; Blomme en Timmermans), maar alleen de laatste publicatie, die van van Blomme en Timmermans, is bestemd voor leerders met een bepaalde moedertaal - het Frans. ${ }^{1}$ Voor het taalpaar dat in de lezing behandeld wordt - het Pools en het Nederlands - zijn er twee oudere publicaties op de markt: één van een meer theoretisch (Prędota, Wymowa) en één van een meer praktisch karakter (Prędota, $O p$ zoek). Enkele uitspraakproblemen van Poolse leerders van het Nederlands zijn ook door de auteur van dit artikel in een publicatiereeks behandeld, maar het onderwerp mag geenszins als uitgeput gezien worden.

Het onderwerp van deze bijdrage is een voorzetting en aanvulling op een meer algemene bijdrage over uitspraakfouten van Poolstalige NVT-leerders (Czerwonka-Wajda). Het eigen onderzoek van de auteur naar uitspraakfouten van Poolse en Duits leerders van het Nederlands ligt ten grondslag aan beide bijdragen. In deze tekst wordt één van de veel voorkomende uitspraakfouten van Poolse leerders onder de loep genomen: de spanningimitatie d.m.v. de invoeging van de glijklanken. Daarbij zien we dat de onderwijspraktijk van belang is waarin de docent met de fonetische creativiteit van de leerders (waaronder ook de invoeging van de glijklanken als een vorm van spanningimitatie door de Poolse leerders) geconfronteerd wordt. Tegelijkertijd valt het onderwerp ook goed samen met het idee van glocalisering van taalonderwijs dat in de laatste jaren populair is geworden. ${ }^{2} \mathrm{De}$ glocalisering in het (taal)onderwijs houdt namelijk in dat naast de globale ook de lokale elementen aan bod komen, waardoor het leren efficiënter wordt. De realisatie van klanken van een vreemde taal (hier: Nederlandse gespannen vocalen) door de leerders met een bepaalde moedertaal (hier: Pools) op een specifieke manier (hier: d.m.v. glijklankinvoeging), is een goed voorbeeld van zo'n locaal element.

\footnotetext{
${ }^{1}$ Interessant is dat het boek van Blomme \& Timmermans een heel specifieke doelgroep heeft, nl. die Franstaligen uit Wallonie en Brussel die het Vlaams-Nederlands willen (of moeten) leren.

${ }^{2}$ Als voorbeeld in het kader van Neerlandistiek kan o.a. de lezing van Frieda Steurs genoemd waarmee het Regionaal Colloquium Neerlandicum 2017 in Wrocław werd afgesloten.
} 
Omdat deze bijdrage het probleem van invoeging van de glijklanken uit een holistisch perspectief wil benaderen, zullen hier zowel theoretische overwegingen aan bod komen, als ook een analyse van authentiek materiaal met het oog op criteria als onderzoeksgroep, frequentie van de afzonderlijke vormen in het corpus en fase in het leerproces. Ik rond af met conclusies en enkele aanwijzingen voor de uitspraakdidactiek.

\section{DE INVOEGING VAN EEN GLIJKLANK \\ - HOE EN WAAROM?}

In deze bijdrage wordt - zoals al vermeld - de invoeging van de glijklanken [j] en [w] in de uitspraak van Poolse leerders van het Nederlands geanalyseerd. Het gaat om een heel specifieke fonetische realisatie van drie $\mathrm{Ne}-$ derlandse gespannen vocalen die geen equivalent in het vocaalsysteem van het Pools hebben: $[\mathrm{e}],[\mathrm{y}]$ en [o]. Het valt op te merken dat de theoretische confrontatieve vergelijking van het Poolse en Nederlandse vocaalsysteem geen verklaring voor een soortgelijke invoeging geeft, want naar verwachting zouden de Nederlandse gespannen vocalen door de articulatorisch meest overeenkomende Poolse vocalen vervangen moeten worden, d.w.z. Nederlandse [e] door Poolse [ $\varepsilon$ ], Nederlandse [y] door Poolse [i] en Nederlandse [o] door Poolse [0], zoals voorgesteld in onderstaande tabel.

Tabel. 1. Vergelijking van geselecteerde Nederlandse en Poolse vocalen en de te verwachten fouten.

\begin{tabular}{|l|l|l|l|}
\hline & NL & PL & $\begin{array}{l}\text { articulatorisch meest overeenkomende Poolse vocaal } \\
(=\text { te verwachten fout })\end{array}$ \\
\hline niet gronde voorklinkers & {$[\mathrm{e}]$} & {$[\varepsilon]$} & {$[\varepsilon][$ - gespannen $]$} \\
\hline gronde voorklinkers & {$[y]$} & ---- & {$[i][$ - gerond $]$} \\
\hline achterklinkers & {$[0]$} & {$[0]$} & {$[0][$ - gespannen] } \\
\hline
\end{tabular}

De invoeging van een glijklank is dus een fonetische realisatie die naast een subsitutie van de Nederlandse vocaal door een Poolse vocaal kan voorkomen. Articulatorisch gezien hebben we in het geval van glijklankinvoeging te maken met een "splitsing" van de Nederlandse gespannen vocaal in twee Poolse klanken (vocaal en glijklank), die na elkaar gerealiseerd worden 
(vgl. ook Kühn 115). Er ontstaan daarbij de volgende vormen (vgl. ook Prędota, Op zoek 12-23):

- i.p.v. de Nederlandse [e] wordt een combinatie van Poolse $[\varepsilon]$ en [j] gerealiseerd,

- i.p.v. de Nederlandse [y] - een combinatie van Poolse [i] en [j] of [j] en $[\mathrm{u}]$,

- en i.p.v. de Nederlandse [o] - een combinatie van Poolse [o] en [w].

Even belangrijk (of misschien zelfs nog belangrijker) is de communicatieve indruk die de glijklankinvoeging achterlaat, namelijk het effect van de spanningimitatie. In het Pools hoort spanning niet bij de distinctieve kenmerken van vocalen. De Poolse leerder moet deze dus in het Nederlands aanleren of op een of andere manier imiteren. De invoeging van de glijklank [j] of [w] na de Poolse vocaal vervult precies die tweede rol. Men zou dus kunnen vermoeden dat we niet met een „neiging“ tot incorrecte uitspraak te maken hebben zoals Prędota het noemt (Prędota, Op zoek 12), maar met een (meer of minder bewuste) beslissing van de spreker die een grondigere analyse vereist.

\section{ANALYSE VAN HET MATERIAAL}

\subsection{ONDERZOEKSPERSONEN}

In deze bijdrage worden data geanalyseerd die van 60 onderzoekspersonen kwamen. Alle onderzochte personen waren studenten Nederlands (BA, voltijds) aan de Universiteit van Wroclaw. Ze waren tussen 19 en 22 jaar oud en hun moedertaal was het Standaard Pools (zonder enige regionale kleur). Hun niveau van het Nederlands op het moment van het experiment was verschillend en varieerde van $\mathrm{A} 1\left(1^{\mathrm{e}}\right.$ studiejaar BA na het eerste semester), $\mathrm{A} 2\left(2^{\mathrm{e}}\right.$ studiejaar $\mathrm{BA}$, aan het begin van het derde semester) tot $\mathrm{B} 1 / \mathrm{B} 2$ $\left(3^{\mathrm{e}}\right.$ studiejaar BA). De onderzoekspersonen hadden verschillende kennis van andere vreemde talen (naast het Nederlands): op basis van hun L2 (de eerste geleerde vreemde taal) waren ze bij een van de onderzoeksgroepen ingedeeld $^{3}$ om na te gaan of de L2 invloed kan hebben op de glijklankinvoeging.

\footnotetext{
${ }^{3}$ Ten opzichte van het originele onderzoek waren de onderzoekspersonen in drie groepen ingedeeld - naast de twee bovengenoemden Poolse groepen was er ook een extra groep Duitstalige personen met Engels als L2 en het Nederlands als L3 of L4 (30 personen). Omdat de invoeging van de glijklank een typisch Pools verschijnsel is, komen de data van de Duitstalige groep niet aan bod.
} 
In de eerste groep waren er studenten met het Duits als L2 (gevorderd) en Nederlands als L3 of L4 (30 personen) en in de tweede groep studenten met het Engels als L2 (gevorderd) en Nederlands als L3 of L4 430 personen).

\subsection{ONDERZOEKSPROCEDURE EN ONDERZOEKSMATERIAAL}

In de onderzoeksprocedure werden de onderzoekspersonen gevraagd om dezelfde tekst van ca. 30 regels voor te lezen. Tijdens het lezen werd de uitspraak van elke testpersoon geregistreerd d.m.v. een dicteerapparaat. Vervolgens werd per onderzoekspersoon / opname de uitspraak van de geselecteerde woorden met [e] (24 stuks), [y] (11 stuks) en [o] (17 stuks) beoordeeld als correct of niet correct. Indien de uitspraak niet correct was, trachtte men de door de proefpersoon uitgesproken klank (of klankencombinatie) te transcriberen. Ten slotte werden de data per onderzoeksgroep verder in kwantitatief en kwalitatief opzicht geanalyseerd.

\subsection{Kwantitatieve analyse}

De uitkomsten van de kwantitatieve analyse per onderzoeksgroep zijn in onderstaande twee tabellen samengevat. Per tabel wordt het aantal correcte realisaties genoemd $\left(2^{\mathrm{e}} \mathrm{kolom}\right)$, als ook de procentuele verdeling van de incorrecte (3de kolom), met name rekening houdend met de substitutie van de correcte Nederlandse vocaal door een andere vocaal en de articulatorische splitsing van de Nederlandse vocaal in de combinatie vocaal+glijklank.

Tabel 2. Realisaties van [e], [y] en [0] in groep 1 (L2 = Duits) en in groep 2 (L2 = Engels).

\begin{tabular}{|c|c|c|c|c|c|c|}
\hline \multirow{2}{*}{$\begin{array}{l}\text { Groep } 1 \\
\text { (L2 = Duits) }\end{array}$} & \multirow[t]{2}{*}{ correct gerealiseerd } & \multicolumn{5}{|c|}{ gesubstitueerd met } \\
\hline & & {$[\varepsilon]$} & & {$[\varepsilon+\mathrm{j}]$} & een ar & re klank \\
\hline \multirow[t]{3}{*}{ [e] } & $43 \%$ & $26 \%$ & & $30 \%$ & $1 \%$ & \\
\hline & correct gerealiseerd & \multicolumn{5}{|c|}{ gesubstitueerd met } \\
\hline & & {$[\mathrm{Y}]$} & {$[u]$} & & {$[i+j] /[j+u]$} & een andere klank \\
\hline [y] & $38 \%$ & $16 \%$ & $40 \%$ & & $4 \%$ & $2 \%$ \\
\hline
\end{tabular}

\footnotetext{
${ }^{4}$ Studenten uit de tweede groep hadden geen kennis van het Duits.
} 


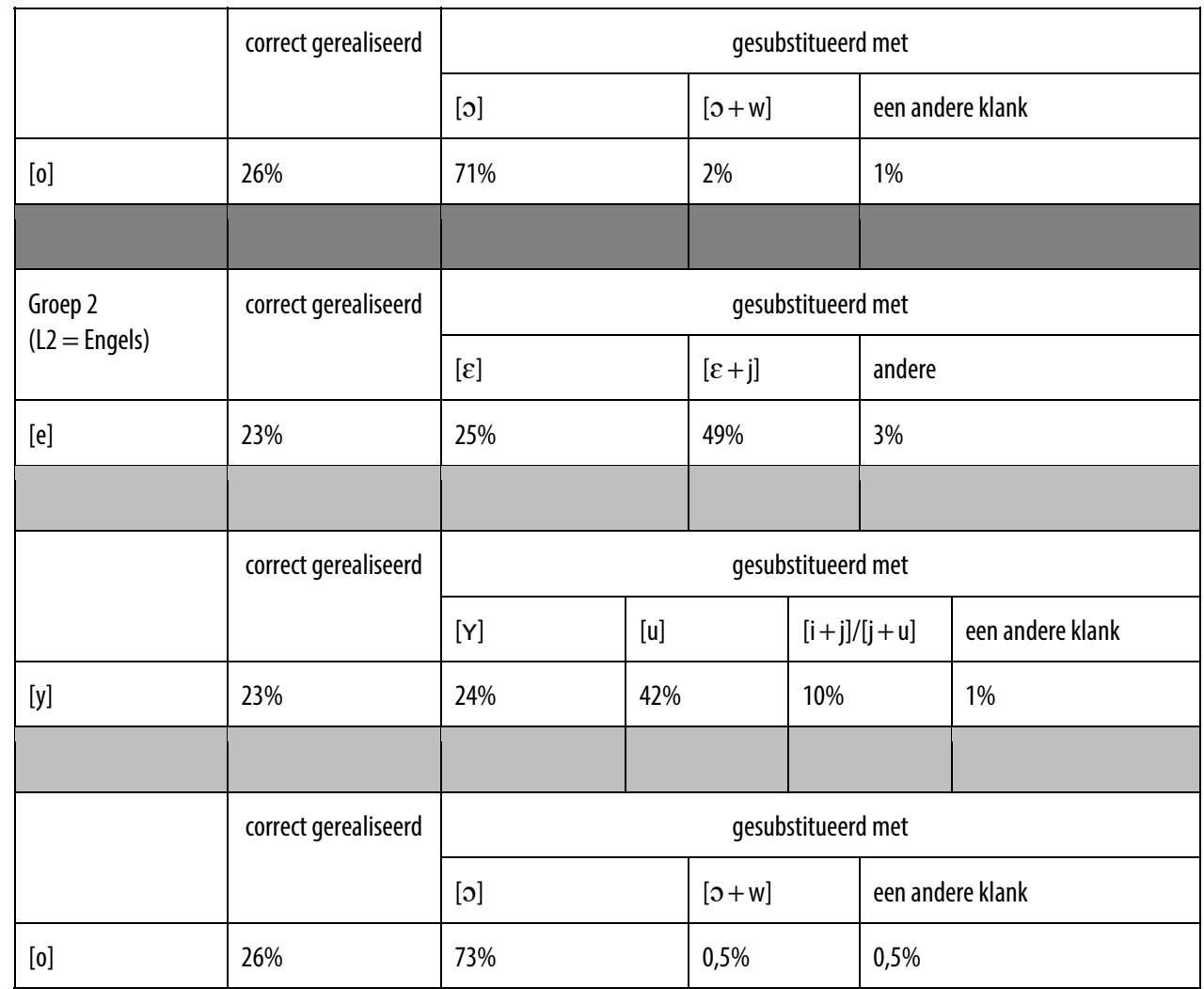

Op basis van de data in de bovenstaande tabel kunnen er enkele opmerkingen worden gemaakt. Ten eerste: de prognose m.b.t. te verwachten fouten (zie Tabel 1) werd alleen in het geval van de Nederlandse gespannen [o] bevestigd, die inderdaad het vaakst door de Poolse niet gespannen [0] gesubstitueerd werd. De Nederlandse gespannen [e] daarentegen werd vaker door de combinatie van twee Poolse klanken $-\left[\varepsilon^{+} \mathrm{j}\right]$ - vervangen dan door de Poolse niet gespannen $[\varepsilon]$. Substitutie van de Nederlandse gespannen $[y]$ door de Poolse [i] kwam niet voor. Ten tweede: in beide groepen werd de substitutie door de combinatie Poolse vocaal+glijklank wel geregistreerd, maar de frequentie ervan was verschillend. Het hoogst was de frequentie in het geval van [e], kleiner in het geval van [y] en laag in het geval van [o]. De verschillen in de frequentie dienen zeker nader in kwalitatief opzicht te worden bestudeerd. En ten derde: de Nederlandse gespannen [y] die door de Poolse leerders het vaakst door de Poolse [u] of Nederlandse [Y] vervangen wordt, is een apart geval, omdat de spelling het beeld wezenlijk verstoort. Maar ook hier was de invoeging van de glijklank vast te stellen - de Nederlandse [y] 
werd ook door de combinatie $[\mathrm{u}+\mathrm{j}]$ gesubstitueerd. We hebben hier met de parallelle invloed van de Poolse spelling en invoeging van de glijklank te maken.

De bijkomende kwalitatieve analyse van de data brengt nog meer interessante resultaten met zich mee, als we het voorkomen van de glijklankinvoeging in verband brengen met het niveau van de testpersonen in het Nederlands. Tabel 4 laat die correlatie goed zien: de invoeging van de glijklank komt in beide groepen het vaakst voor op A2-niveau. Dat duidelijke verband vereist ook een grondigere analyse vanuit kwalitatief perspectief.

Tabel 3. Invoeging van de glijklanken en het niveau van het Nederlands.

\begin{tabular}{|c|c|c|c|c|}
\hline \multicolumn{5}{|c|}{ Groep 1 (L2 = Duits) } \\
\hline Niveau & $\mathrm{A} 1$ & A2 & $B 1+B 2$ & Samen \\
\hline$[\varepsilon+\mathrm{j}]$ & $6 \%$ & $19 \%$ & $5 \%$ & $=30 \%$ \\
\hline$[\mathrm{i}+\mathrm{j}] /[\mathrm{u}+\mathrm{j}]$ & $0 \%$ & $4 \%$ & $0 \%$ & $=4 \%$ \\
\hline$[0+w]$ & $0 \%$ & $2 \%$ & $0 \%$ & $=2 \%$ \\
\hline \multicolumn{5}{|c|}{ Groep 2 (L2 = Engels) } \\
\hline Niveau & $\mathrm{A} 1$ & A2 & $B 1+B 2$ & Samen \\
\hline$[\varepsilon+\mathrm{j}]$ & $7 \%$ & $26 \%$ & $16 \%$ & $=49 \%$ \\
\hline$[\mathrm{i}+\mathrm{j}] /[\mathrm{u}+\mathrm{j}]$ & $0 \%$ & $7 \%$ & $3 \%$ & $=10 \%$ \\
\hline$[0+w]$ & $0 \%$ & $0,5 \%$ & $0 \%$ & $=0,5 \%$ \\
\hline
\end{tabular}

\subsection{Kwalitatieve analyse en discussie}

De kwantitatieve analyse heeft enkele interessante resultaten opgeleverd, o.a. de bijzondere situatie rond [y], de verschillen in de frequentie van de glijklankinvoeging bij de afzonderlijke Nederlandse gespannen vocalen en het 
verband tussen het aantal glijklankinvoegingen en het niveau van het Nederlands onder de proefpersonen. Hierna worden de bovengenoemde kwantitatieve resultaten vanuit kwalitatief opzicht geanalyseerd en bediscussieerd.

\subsubsection{WaArom Vormt De [Y] Een apart GeVal?}

De gespannen [y] is een moeilijke klank voor Poolse leerders, omdat er in het fonetisch systeem van het Pools geen geronde voorklinkers zijn. De Poolse leerders moeten dus leren in de articulatie het gebruik van predorsum en geronde lippen te combineren. Maar er komt er nog een kwestie bij die blijkbaar veel invloed heeft op articulatorisch prestaties: de spelling. In de Nederlandse spelling wordt de [y] met twee grafemen weergegeven: $\langle\mathrm{u}\rangle$ of $\langle\mathrm{uu}\rangle$. Dit is in twee opzichten problematisch: enerzijds valt deze spelling met de spelling van de Nederlandse niet gespannen [Y] samen (bv. Nl. buren vs. Nl. bus) en anderzijds met de spelling van de Poolse [u] die ook met het grafeem $\langle\mathrm{u}\rangle$ gemarkeerd wordt (bijv. Nl. buren vs. Pl. burek). De incorrecte uitspraak van $[\mathrm{y}]$ in de uitspraak van Poolse leerders van het Nederlands wordt dus vooral veroorzaakt door de invloed vanuit de spelling van hun moedertaal (substitutie van $[\mathrm{y}]$ door $[\mathrm{u}]$ ), maar aan de andere kant wordt deze ook door de spelling van het Nederlands zelf beïnvloed (substitutie van [y] door [Y]). Dit is een heel goed voorbeeld van de ingewikkelde relaties en wederzijdse invloeden van spelling en uitspraak van de moedertaal en de vreemde taal waarop Nagy in zijn artikel over het aanleren van de Nederlandse uitspraak wijst (149).

$\mathrm{T} 1$

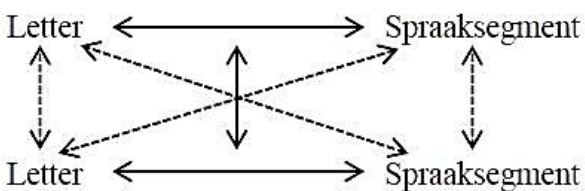

Afbeelding 1. Relatie en wederzijdse invloeden tussen T1 (L1, moedertaal) en T2 (L2, vreemde taal) op het gebied van de uitspraak en spelling naar Nagy (149).

\subsubsection{WAarom is DE FREQUENTIE VAN GLIJKLANKINVOEgING ANDERS} BIJ [E], [Y] EN [O]?

De [y] is zoals in 2.4.2 uitgelegd, een apart geval. Hier speelt namelijk de grafemische interferentie (uit het Pools en uit het Nederlands) een cruciale 
rol en de glijklankinvoeging komt om die reden minder voor (eventueel in combinatie met grafemische interferentie). Maar dan blijft de vraag over waarom er zoveel glijklankinvoeging is in het geval van [e] en zo weinig in het geval van [o]. Hier zijn enkele potentiële verklaringen voor.

Ten eerste kan het verband houden met de wederzijdse beïnvloeding van het articulatieproces en het auditieproces. De verticale beweging van de predorsum vereist namelijk meer spanning van de gezichtsspieren dan de verticale beweging van de postdorsum, omdat de oppervlakte van de predorsum groter is en omdat de predorsum bij de articulatie van [e] hoger gaat dan de postdorsum bij de productie van [o]. Om die reden is de spanning tijdens de productie van [e] in de auditie beter waar te nemen. En omdat de spanning auditief beter waarneembaar is, wordt ze ook vaker in de articulatie gerealiseerd en ook vaker geïmiteerd d.m.v. glijklankinvoeging. De glijklankinvoeging in het geval van [e] kan ook worden gestimuleerd door invloed van een andere Nederlandse klank die in het fonetisch systeem van het Pools ontbreekt - de diftong [عi]. In de uitspraak van Poolstalige studenten Nederlands vallen beide Nederlandse klanken vaak samen, d.w.z. dat de [عi] ook als een combinatie van $[\varepsilon]$ en $[j]$ wordt uitgesproken. Ze worden ook vaak verwaard in de spelling (bijv. aanweizig i.p.v aanwezig). Of de Poolstaligen beide klanken daadwerkelijk op een vergelijkbare manier auditief perciperen, valt nog te onderzoeken.

Nog een andere factor die hier een rol kan spelen, is de kwaliteit van de uitspraak van de Nederlandstaligen zelf. In de vakliteratuur wordt steeds vaker op de diftongisering van [e] in het noordelijk deel van het Nederlands taalgebied gewezen (vgl. Van de Velde 159-172). Het is dus best mogelijk dat studenten die steeds vaker geconfronteerd worden met de dediftongiseerde uitspraak van [e], de [e] zelf op een vergelijkbare manier beginnen uit te spreken (vooral als de gediftongiseerde uitspraak articulatorisch voor hen makkelijker over te nemen is). Zeker is meer onderzoek op dit gebied nodig.

\subsubsection{WAAROM KOMT DE GLIJKLANKINVOEGING HET VAAKST VOOR OP} A2-NIVEAU?

Om het antwoord op deze vraag te kunnen geven, moeten we weer dieper op de wederzijdse beïnvloeding van articulatie en auditie ingaan. De auditieve en articulatorische competentie in een vreemde taal stijgt naarmate de leerder meer contact met deze taal heeft, maar verloopt niet noodzakelijk parallel. Omdat de Poolse leerders in het begin niet eraan gewend zijn gespan- 
nen en ongespannen vocalen auditief te onderscheiden (in het Pools vervult de spanning geen distinctieve rol), vervangen ze de Nederlandse gespannen [e] en [o] eerst door een niet gespannen vocaal vanuit het Pools, d.w.z. met $[\varepsilon]$ en [0]. Maar na twee semesters intenstieve studie (420 lesuren praktisch Nederlands, waaronder 30 uur praktische fonetiek en 30 uur fonetiek en fonologie), hebben ze al genoeg contact met het gesproken Nederlands gehad om het auditieve verschil tussen Nederlandse gespannen en niet gespannen klanken te leren herkennen. Dit veroorzaakt dat zij het verschil ook in de articulatie willen weergeven, maar hun articulatorische competentie is nog niet genoeg ontwikkeld om de spanning correct te realiseren. De leerders imiteren dus de spanning door na de Poolse niet gespannen vocaal $[\varepsilon]$ of [0] een extra glijklank in te voegen. In de laatste studiefase (na het 3 de studiejaar) is het aantal correcte realisaties van de gespannen [e] of [o] in het Nederlands het grootst, omdat de articulatorische competentie de auditieve competentie inhaalt.

Samenvattend kan dus worden gezegd dat het voorkomen van de glijklankinvoeging in de uitspraak van de Nederlandse gespannen vocalen [e] en [o] als een tussenfase gezien kan worden wat een teken is van geleidelijke ontwikkeling van acticulatorisch en auditieve competenties in het Nederlands.

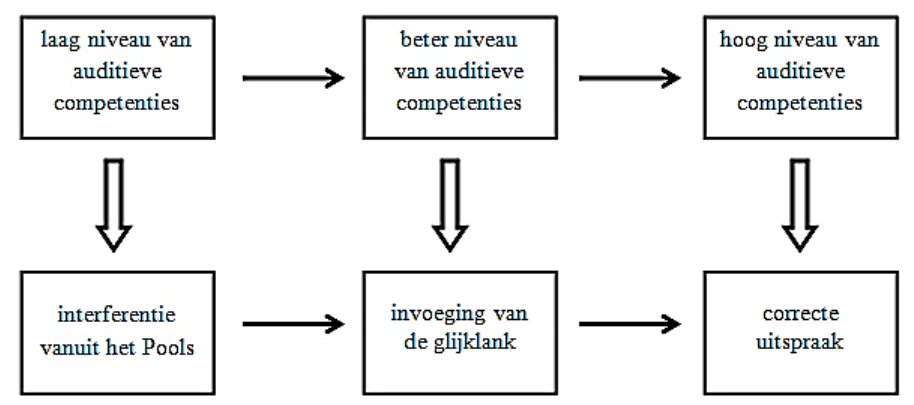

Afbeelding 2. De ontwikkeling van articulatorisch-auditieve competentie met glijklankinvoeging als tussenfase.

\section{CONCLUSIES EN ENKELE AANWIJZINGEN VOOR DE UITSPRAAKDIDACTIEK}

Op basis van de uitkomsten van de kwantitatieve en kwalitatieve analyse kunnen enkele conclusies en aanwijzingen voor de uitspraakdidactiek worden geformuleerd die tegelijkertijd als elementen van glocalisering in het uitspraakonderwijs gezien kunnen worden. Ten eerste: de glijklankinvoeging 
is er een bewijs voor dat er bij taalcontact een grijze zone ontstaat waarin op alle taalniveaus - dus ook in de uitspraak - veel gebeurt. Naast het simpel overnemen van klanken vanuit de moedertaal, experimenteren de leerders met verschillende (overgangs)vormen, waaronder ook met de glijklankinvoeging. Vaak vallen de leerders ook ten offer aan verschillen tussen spelling in de moedertaal en vreemde taal. Ten tweede: de glijklankinvoeging als poging tot spanningimitatie komt in de uitspraak van Poolse leerders voor en moet in het didactisch proces van de Nederlandse uitspraak in aanmerking worden genomen. Dit geldt vooral voor de Nederlandse gespannen [e] die het vaakst in een combinatie van de Poolse niet gespannen $[\varepsilon]$ en de glijklank [j] gesplitst wordt. ${ }^{5}$ Enerzijds kan de invoeging van de glijklank na de Poolse vocaal in het algemeen als een teken van worden gezien dat die auditief-articulatorische competentie van de leerders zich ontwikkelt en dat het leerproces in de juiste richting gaat. ${ }^{6}$ Anderzijds (en dit ten derde) brachten de resultaten van het onderzoek nieuwe vragen met zich mee, vooral m.b.t. de hoge frequentie van de glijklankinvoeging na $[\varepsilon]$. Er moet zeker verder worden onderzocht, in hoeverre de realisering van de Nederlandse [e] als $[\varepsilon+\mathrm{j}]$ aan de ene kant gestimuleerd wordt door het samenvallen van de Nederlandse [e] en [عi] in de auditieve perceptie van Poolse leerders en aan de andere kant in hoeverre deze realisering toe te schrijven is aan de diftongisering van $[\mathrm{e}]$ in het noordelijk deel van het Nederlands taalgebied.

\section{BIBLIOGRAFIE}

Blomme, Ines, Annelies Nordin en Johanna Potargent. Nu versta ik je! Uitspraak Nederlands voor anderstaligen. Leuven, Acco, 2009.

Blomme, Ines, en Bernardette Timmermans. Klink klaar. Uitspraak van het Nederlands voor Franstaligen. Leuven, Davidsfonds, 2016.

Czerwonka, Zuzanna. “(Aus)Sprache im Unterricht: die prädorsalen ungerundeten Vokale der Niederländischen als Ausspracheproblem für polnische Muttersprachler - eine Signaluntersuchung". Sprache in Wissenschaft und Unterricht: Akten des 23. internationalen

\footnotetext{
${ }^{5}$ De invoeging van de glijklank is ook te verwachten bij Poolse leerders die andere populaire Germaanse vreemde talen leren waarin spanning een distinctief kenmerk van vocalen is, bijv. Duits (vooral $[\mathrm{e}] \rightarrow[\varepsilon]+[\mathrm{j}]$, vgl. Morciniec en Prędota 109) of Engels (vooral $[\mathrm{o}] \rightarrow[\mathrm{o}]+[\mathrm{w}]$ ). Bovendien eist de kwestie van hogere frequentie van glijkklankinvoeging in het geval van [e] verder onderzoek, vooral t.o.v. de invloed van perceptie op de articulatie (zie 2.4.2).

${ }^{6}$ Vanzelfsprekend moet de verdere ontwikkeling van de auditief-articulatorische competentie verder gecontroleerd worden, opdat in de laatste fase de correcte, gespannen uitspraak van Nederlandse vocalen bereikt wordt.
} 
Linguistenkonferenz Karpacz 14.-16.05.2012, red. Edyta Błachut \& Adam Gołębiewski, Wrocław, Oficyna Wydawnicza ATUT/Dresden, Neisse Verlag, 2013, pp. 58-67.

Czerwonka, Zuzanna. "De vocaalsystemen van het Pools, Duits en Nederlands-polyconfrontatieve analyse en didactische implicaties". Neerlandistische ontmoetingen: Trefpunt Olomouc, red. Wilken Engelbrecht en Bas Hamers, Univerzita Palackého v Olomouci, 2010, pp. 255-262.

Czerwonka, Zuzanna. "Die prädorsal-gerundeten niederländischen Vokale als Ausspracheproblem für polnische und deutsche Studierende der Niederlandistik - eine Signaluntersuchung". Motoren der heutigen (germanistischen) Linguistik, red. Edyta Błachut en Adam Gołębiewski, Wrocław, Oficyna Wydawnicza ATUT, 2012, pp. 27-38.

Czerwonka, Zuzanna. "Nederlandse geronde voorklinkers als fonetisch probleem voor Poolse ed Duitse moedertaalsprekers - een theoretisch en praktisch overzicht". Neerlandica Wratislaviensia, vol. 21, 2012, pp. 45-59.

Czerwonka-Wajda, Zuzanna. "Modificatie, substitutie of uitbreiding? Over de articulatorische karakteristiek en classificatie van uitspraakfouten van leerders van het Nederlands als vreemde taal". Neerlandica Wratislaviensia, vol. 27, 2017, pp. 55-76.

Kampen, Hinke van, Vita Olijhoek, Ruud Stumpel en Chris van Veen. Uitspraaktrainer in de les. Uitspraakverbetering voor anderstaligen. Amsterdam, Boom, 2011.

Kühn, Antje. Kontrastive Phonetik der romanischen Sprachen. Diskurs-Verlag, 2010.

Morciniec, Norbert, en Stanisław Prędota. Podręcznik wymowy niemieckiej. Wydawnictwo Naukowe PWN, 1995.

Nagy, Roland. "Transcriptie: brug over troebel water?" Nederlands in het perspectief van uitspraakverwerving, (Lage Landen Studies 2), red. Laurent Rasier, Vincent van Heuven, Bart Defranq \& Philippe Hiligsmann, Gent, Academia Press, 2011, 143-162.

Prędota, Stanisław. Op zoek. Laat de klanken klinken. Oefeningen voor de uitspraak van het Nederlands. Wydawnictwo Naukowe PWN, 2000.

Prędota, Stanisław. Wymowa języka niderlandzkiego. Wydawnictwo Uniwersytetu Wrocławskiego, 1998.

Sleeuwen, Gabi van, en Anneloes Spaan. Nu versta ik je! Uitspraak Nederlands voor anderstaligen. Leuven, Acco, 2013.

Thio, Karolien \& Margreet Verboog. 2013. Verstaanbaar spreken. Een handleiding uitspraakonderwijs voor docenten Nederlands als tweede taal. Bussum, Couthino 2013.

Timmermans, Bernardette. Klink Klaar. Uitspraak- en intonatiegids voor het Nederlands. Leuven, Davidsfonds, 2013.

Veen, Chris van, Hinke van Kampen, Vita Olijhoek en Ruud Stumpel. Goed gezegd: uitspraak voor anderstaligen. Antwerpen, Wpg Uitgevers, 2011.

\section{WPROWADZENIE PÓŁSAMOGŁOSEK [J] I [W] \\ JAKO PRÓBY REALIZACJI PRONUNCJACJI NIDERLANDZKICH \\ SAMOGŁOSEK [E], [Y] ORAZ [O] PRZEZ POLSKICH STUDENTÓW}

Streszczenie

W artykule został poruszony problem wymowy niderlandzkich samogłosek [e], [o] i [y] przez osoby polskojęzyczne. Obok prostego zastąpienia danej niderlandzkiej napiętej samogłoski pol- 
ską samogłoską regularnie pojawia się forma kombinowana $\mathrm{z}$ dodatkową półsamogłoską [j] lub [w] realizowaną po polskiej samogłosce. Szczegółowa analiza wskazuje, że poszczególne połączenia samogłoska+ półsamogłoska mają różną frekwencję oraz że pojawiają się częściej wraz ze wzrastającym poziomem języka niderlandzkiego (od poziomu A2). Dodanie półsamogłoski można więc uważać za próbę imitacji napięcia (które nie jest w języku polskim cechą dystynktywną) i znak rozwijającej się sprawności audytywnej i artykulacyjnej.

Słowa kluczowe: fonetyka; wymowa; niderlandzki; samogłoski napięte; półsamogłoski; dydaktyka wymowy.

\author{
THE INTRODUCTION OF THE GLIDES [J] AND [W] \\ AS AN ATTEMPT TO IMPLEMENT THE PRONUNCIATION \\ OF THE DUTCH VOWELS [E], [Y] AND [O] BY POLISH LEARNERS \\ $\mathrm{Sum} \mathrm{m}$ a r y
}

The paper addresses the problem of the pronunciation of [e], [o] and [y] by Polish learners of Dutch. Next to a simple substitution of the three tense Dutch vowels by (lax) Polish vowels it can frequently be noted that an extra glide [j] or [w] is being added after the Polish vowel. The detailed analysis reveals that frequency of the vowel+glide combination differs and that the epenthesis of glides is correlated with learners' level of Dutch (it starts around the A2 level). Adding the glide may therefore be seen as an attempt to imitate tension (as tension is not a distinctive feature in Polish) and proof of development of perception and pronunciation skills.

Key words: phonetics; pronunciation; Dutch; tense vowels; glides; pronunciation teaching. 